\title{
Proposição de um Modelo Empírico para Determinação das Temperaturas Críticas Durante Resfriamento Contínuo em Zonas Termicamente Afetadas de Aços IF Soldados pelo Processo TIG
}

\author{
Ana Luiza Soares Cezário ${ }^{1}$, Rodrigo Rangel Porcaro ${ }^{1}$, Geraldo Lúcio de Faria ${ }^{1}$ (]) \\ ${ }^{1}$ Universidade Federal de Ouro Preto - UFOP, Rede Temática em Engenharia de Materiais, Ouro Preto, MG, Brasil.
}

Como citar: Cezário ALS, Porcaro RR, Faria GL. Proposição de um modelo empírico para determinação das temperaturas críticas durante resfriamento contínuo em zonas termicamente afetadas de aços IF soldados pelo processo TIG. Soldagem \& Inspeção. 2019;24:e2420. https://doi.org/10.1590/0104-9224/SI24.20

\begin{abstract}
Resumo: Aços IF são amplamente empregados na indústria automobilística. No decorrer das aplicações de soldagem, eles passam pela transformação de fase austenita $(\gamma) \rightarrow$ ferrita $(\alpha)$ que ocorre por nucleação e crescimento de grão e, em condições isotérmicas, é descrita pela equação JMAK. Todavia, as transformações de fases pós-soldagem acontecem a partir de resfriamento contínuo. Assim, o presente trabalho caracterizou a cinética de transformação $\gamma \rightarrow \alpha$ e propôs um modelo empírico para prever as temperaturas críticas durante o resfriamento contínuo em zonas termicamente afetadas de três tipos de aços IF. Amostras dos aços foram submetidas a ensaios dilatométricos com diferentes taxas de resfriamento contínuo. Determinaram-se as temperaturas críticas de transformação de fase $(\nu \rightarrow \alpha)$ e obteve-se uma equação empírica que correlacionou a temperatura crítica com a taxa de resfriamento e que viabilizou a previsibilidade da cinética de transformação de fases. Processo de soldagem TIG mecanizado foi aplicado nos aços IF com monitoramento de ciclos térmicos e, em regiões da ZTA com condições de austenitização e taxa de resfriamento similares às utilizadas nos ensaios dilatométricos, verificou-se que a equação empírica obtida é uma alternativa viável para prever as temperaturas críticas e a microestrutura durante o resfriamento contínuo na ZTA destes materiais.
\end{abstract}

Palavras-chave: Decomposição da austenita; Modelos cinéticos; Previsibilidade; Soldagem de aços IF.

\section{Proposition of an Empirical Model for Determination of Critical Temperatures During Continuous Cooling in Heat Affected Zones of IF Steels Welded by the TIG Process}

\begin{abstract}
IF steels are widely used in the automotive industry. In the course of the welding applications, they undergo the transformation of austenite $(\gamma) \rightarrow$ ferrite $(\alpha)$ phase that occurs by nucleation and grain growth and, under isothermal conditions, is described by the JMAK equation. However, post-weld phase transformations occur under continuous cooling conditions. Thus, the present work characterized the transformation kinetics $\gamma \rightarrow \alpha$ and proposed an empirical model to predict critical temperatures during continuous cooling in heat affected zones of three types of IF steels. Samples of the steels were submitted to dilatometric tests with different rates of continuous cooling. The critical phase transformation temperatures $(\nu \rightarrow \alpha)$ were determined and an empirical equation was obtained which correlated the critical temperature with the cooling rate, which enabled the predictability of phase transformation kinetics. Mechanized TIG process was applied to IF steels with thermal cycling monitoring and, in regions of the HAZ with austenitizing conditions and cooling rates similar to those used in the dilatometric tests, it was verified that the obtained empirical equation is a viable alternative to predict the critical temperatures and the microstructure during the continuous cooling in the HAZ of these steels.
\end{abstract}

Key-words: Austenite decomposition; Kinetic models; Predictability; Welding of IF steel.

\section{Introdução}

Os aços IF, "Interstitial Free", são aços livres de elementos intersticiais, como C e N, amplamente empregados na indústria automobilística, sendo usualmente conformados e soldados [1-4]. Neste segmento da indústria, seja para adequação de processos de conformação a quente, assim como para controle das microestruturas pós-soldagem, o entendimento a respeito

Recebido: 10 Maio, 2019. Aceito: 29 Jul., 2019

E-mails: analuizasc@yahoo.com.br (ALSC), geraldolfaria@yahoo.com.br (GLF)

(i) Este é um artigo publicado em acesso aberto (Open Access) sob a licença Creative Commons Attribution Non-Commercial, que permite uso, distribuição e reprodução em qualquer meio, sem restrições desde que sem fins comerciais e que o trabalho original seja corretamente citado. 
da cinética das transformações das fases primárias se faz necessário, principalmente levando-se em consideração a diversidade de possíveis composições químicas que aços da classe IF podem possuir.

Durante as usuais aplicações de soldagem de componentes dos automóveis [2,4], os aços IF passam pela transformação de fase austenita $(\gamma) \rightarrow$ ferrita $(\alpha)$ que em função do tamanho de grão das fases, partições químicas e outros aspectos, têm um impacto significativo na metalurgia do produto. A cinética de transformação de fase $\gamma \rightarrow \alpha$, em condições isotérmicas, ocorre por nucleação e crescimento de grão e é descrita pelo modelo clássico de Johson-Mehl-Avrami-Kolmogorov (JMAK) dado pela Equação 1 [5-7]. Embora essa equação tenha sido fisicamente descrita para transformações de fases em condições isotérmicas, muitos autores utilizam adaptação empírica do modelo JMAK para descrever a cinética de transformação de fases para resfriamentos contínuos e mostram que para alguns materiais é satisfatório, apesar da interpretação física das constantes não ser mais a mesma prevista inicialmente para os sistemas isotérmicos [8-11]. Gómez et al. adaptaram o modelo de JMAK e propuseram uma equação para descrever a cinética de transformação $\gamma \rightarrow \alpha$, obtiveram uma boa previsão da cinética de transformação de ferrita proeutetóide, exceto no início da transformação [8]. Singh et al. avaliaram o comportamento da transformação $\gamma \rightarrow \alpha$ em dois aços com teores de $C$ ultra baixos submetidos a diferentes taxas de resfriamento e examinaram a viabilidade de se utilizar o modelo JMAK. A análise dos dados experimentais mostrou precisão para apenas uma taxa de resfriamento para cada um dos aços estudados. Concluíram que a adaptabilidade do modelo clássico de JMAK para resfriamento não isotérmicos não é eficiente para descrever a cinética de transformação $\gamma \rightarrow \alpha$ para qualquer taxa de resfriamento [9].

$$
y=1-\exp \left(-k t^{n}\right)
$$

Sabendo-se que as transformações de fases pós-soldagem, assim como na grande maioria dos processos metalúrgicos, acontecem a partir da aplicação de resfriamento contínuo e tendo em vista que existem poucos trabalhos na literatura que exploram a cinética de transformação de fases em processos não isotérmicos em aços IF, apesar da relevância do tema como destacam publicações recentes [12], o presente trabalho teve como principal objetivo propor um modelo empírico para prever a cinética de transformação de fase $\psi \rightarrow \alpha$ durante resfriamento contínuo em zonas termicamente afetadas de aços IF soldados pelo processo TIG (Tungsten Inert Gas), a partir de ensaios de dilatometria. Além disso, amostras de três aços IF foram submetidas a soldagem TIG autógena mecanizada e com monitoramento de ciclos térmicos em regiões da ZTA com temperatura de austenitização e taxas de resfriamento similares às utilizadas nos ensaios dilatométricos, para validação da hipótese de previsibilidade.

\section{Materiais e Métodos}

\subsection{Caracterização do estado de entrega}

Foram avaliados três aços IF com diferentes composições: (i) IF estabilizado com titânio (IF-Ti); (ii) IF estabilizado com nióbio (IF-Nb); e (iii) IF estabilizado com titânio e nióbio (IF-TiNb). A análise química dos materiais foi realizada com o auxílio de três equipamentos: LECO-CS844 para determinação das concentrações de C e S por meio da técnica de absorção de infravermelho após fusão; LECO-TC436DR para determinação da concentração de N por termocondutividade após fusão e Thermo ARL-4460 para determinação da concentração dos demais elementos por espectrometria de emissão óptica.

As microestruturas das amostras em seu estado de entrega foram caracterizadas a partir dos procedimentos padrão de preparação metalográfica [13] e, em seguida, foram atacadas com reativo químico Nital $2 \%$. Posteriormente, essas amostras foram analisadas com o auxílio do microscópico óptico Leica modelo DM2700M. O tamanho médio dos grãos ferríticos foi medido com o auxílio do software Image J por meio do método dos interceptos. Ademais, as amostras foram submetidas a ensaios de microdureza Vickers em um microdurômetro digital do fabricante Pantec, utilizando-se uma carga de 50gf e o tempo de aplicação de 10s. Para o cálculo da média das microdurezas Vickers das amostras de cada aço IF analisado, foram realizadas 16 medições aleatórias [14].

\subsection{Caracterização da cinética de transformação de fases}

Após a etapa de caracterização do estado de entrega, corpos de provas cilíndricos de cada um dos aços IF foram confeccionados com dimensões padronizadas de aproximadamente $10 \mathrm{~mm}$ de comprimento e $3 \mathrm{~mm}$ de diâmetro. Os cilindros foram usinados a partir da mesma chapa correspondente a cada um dos aços IF analisados. Tiras com largura de 4,5mm foram cortadas e usinadas em torno de precisão até que adquirissem o formato cilíndrico nas dimensões citadas. Para resguardar as características químicas e microestruturais da chapa, ressalta-se que os cilindros não passaram por nenhum outro processamento além do mencionado. Os ensaios dilatométricos foram realizados no dilatômetro de têmpera R.I.T.A. L78 da fabricante LINSEIS e consistiram na austenitização de cada uma das amostras a uma taxa constante de $5^{\circ} \mathrm{C} / \mathrm{s}$ até a temperatura de $1100{ }^{\circ} \mathrm{C}$, na qual foram mantidas por 3 minutos. Em seguida, cada amostra foi resfriada a uma determinada taxa de 
resfriamento constante $\left(0,5^{\circ} \mathrm{C} / \mathrm{s}, 1^{\circ} \mathrm{C} / \mathrm{s}, 3{ }^{\circ} \mathrm{C} / \mathrm{s}, 5^{\circ} \mathrm{C} / \mathrm{s}, 10^{\circ} \mathrm{C} / \mathrm{s}, 20^{\circ} \mathrm{C} / \mathrm{s}\right.$ e $\left.100^{\circ} \mathrm{C} / \mathrm{s}\right)$. A austenitização até a temperatura de $1100{ }^{\circ} \mathrm{C}$ foi escolhida por representar bem uma região da ZTA onde se verifica completa austenitização do material. Além disso, na etapa correspondente à simulação física de soldagem, essa é uma temperatura de pico operacionalmente fácil de se caracterizar, uma vez que seria uma região relativamente distante da zona fundida.

Posteriormente, as microestruturas das amostras provenientes dos ensaios dilatométricos foram caracterizadas e submetidas a ensaios de microdureza Vickers utilizando-se uma carga de 50gf e tempo de aplicação de 10s. Para o cálculo da média das microdurezas, foram realizadas 16 medições aleatórias em cada uma das amostras.

$O$ ensaio dilatométrico fornece dados referentes à variação relativa do comprimento do corpo de prova $(\Delta L / L)$ em função da temperatura instantânea do sistema. Após a realização dos ensaios, os dados obtidos nos resfriamentos contínuos foram extraídos e transferidos para o software para determinação das temperaturas críticas de transformação de fase $\gamma \rightarrow \alpha$ pelo método das derivadas. Esse método permite analisar o momento no qual a derivada da curva dilatométrica começa a se desviar da linearidade, indicando o início da transformação de fase, e o momento no qual a derivada retoma a linearidade, indicando o fim da transformação de fase [15].

Com o intuito de se obter uma previsibilidade das temperaturas de início e fim de transformação de fase $\gamma \rightarrow \alpha$ para uma taxa qualquer de resfriamento no intervalo de $0,5^{\circ} \mathrm{C} / \mathrm{s}$ a $100{ }^{\circ} \mathrm{C} / \mathrm{s}$, foi proposta uma relação empírica entre as temperaturas críticas e a taxa de resfriamento para cada aço IF estudado, apresentada pela Equação 2, onde $T$ é a temperatura crítica, taxa é a taxa de resfriamento e $y_{0}, A$ e $B$ são constantes de ajuste.

$T=y_{0}+A^{*} \exp \left(B^{*} \operatorname{tax} a\right)$

As curvas dilatométricas obtidas durante o resfriamento, além de fornecer as temperaturas críticas Ar3 e Ar1 medidas experimentalmente, também foram utilizadas para estudo da cinética de formação da ferrita a partir de diferentes taxas de resfriamento contínuo considerando a adaptação do modelo clássico JMAK. Assim, as frações de austenita e de ferrita obtidas durante o resfriamento de cada uma das amostras dos diferentes aços IF foram determinadas pela regra da alavanca [16,17] durante toda a transformação e, posteriormente os gráficos de fração de austenita e de ferrita em função do tempo foram construídos. Em cada gráfico fração em função do tempo, foi realizado o ajuste considerando o modelo JMAK (Equação 1), que por sua vez permitiu a determinação de constantes que serviram como parâmetros de entrada para uma posterior simulação da cinética de formação da ferrita. Após a simulação da cinética, foi possível encontrar quais seriam as temperaturas críticas considerando o modelo JMAK e compará-las com as obtidas experimentalmente e com o TRC calculado a partir da relação empírica proposta neste trabalho e apresentada como a Equação 2.

\subsection{Simulação física de soldagem e validação de previsibilidade}

Com o objetivo de verificar a aplicabilidade do modelo proposto na previsão de microestruturas obtidas a partir da soldagem dos aços, experimentos de soldagem TIG autógena foram realizados, Figura 1a. Para os experimentos, foram utilizadas chapas dos três aços IF com $3 \mathrm{~mm}$ de espessura e termopares do tipo $\mathrm{K}$ foram soldados nas faces inferiores das chapas por resistência elétrica (Figura 1b) para monitoramento dos ciclos térmicos. Antes da soldagem, as chapas passaram por um processo de desbaste em uma desbastadeira elétrica com uma cinta de lixa de carboneto de silício de 60\#, com refrigeração em água. Realizou-se um cordão de solda autógeno no centro da chapa (Figura 1a). Os parâmetros do processo de soldagem mecanizada TIG foram ajustados de modo a se obter uma temperatura de pico igual àquela utilizada nos ensaios dilatométricos $\left(1100^{\circ} \mathrm{C}\right)$ na face inferior das chapas. Foram utilizadas as seguintes condições operacionais: uma fonte de energia com corrente constante de $85 \mathrm{~A}$ e tensão de $11 \mathrm{~V}$, a velocidade do eletrodo durante a soldagem TIG autógena foi de $2,4 \mathrm{~mm} / \mathrm{s}$ e fluxo de gás argônio de 10L/min para proteção da solda e do eletrodo. Em seguida, as amostras soldadas passaram por procedimentos de caracterização microestrutural em seção transversal no centro do cordão (Figura 1c), principalmente na região que teve a temperatura de pico igual àquela aplicada nos ensaios de dilatometria $\left(1100^{\circ} \mathrm{C}\right)$. As amostras soldadas foram ainda submetidas a ensaios de microdureza Vickers, nas mesmas condições aplicadas aos corpos de provas de dilatometria, segundo os perfis esquemáticos apresentados pela Figura 1c.

Na Figura 1c pode-se observar também o procedimento adotado para medida da largura da ZTA nas amostras soldadas: imagens macrográficas foram adquiridas em estereoscópio óptico e a largura da ZTA foi medida na superfície das amostras a partir de processamento de imagens no software ImageJ. Pelo menos quatro campos, em duas posições diferentes no centro do cordão, foram utilizados para as medidas em cada um dos aços IF soldados. 


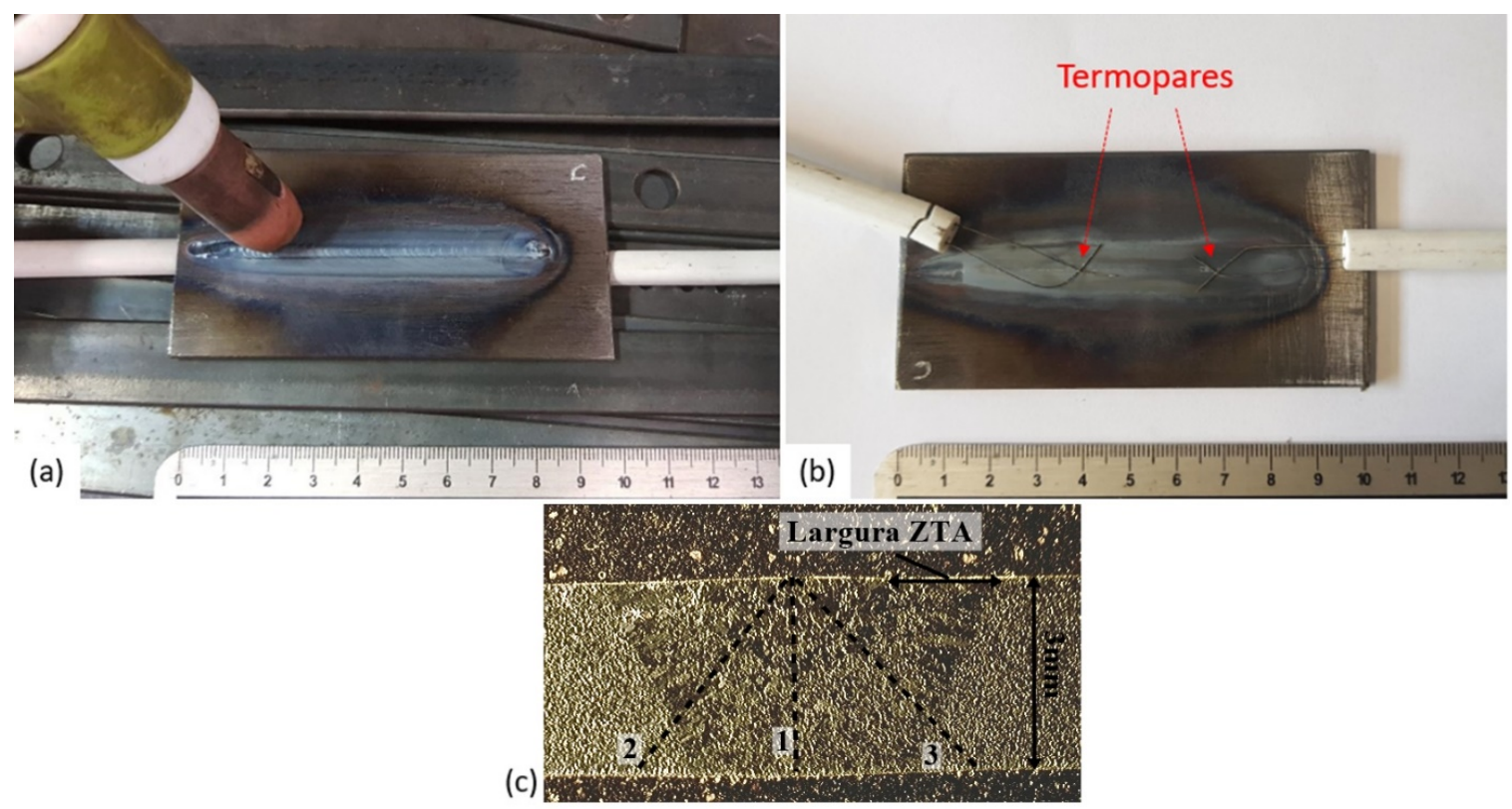

Figura 1. (a) Experimento de soldagem TIG autógena nos aços IF; (b) Termopar do tipo K soldado por resistência elétrica na superfície inferior da chapa soldada; (c) Ilustração dos perfis de microdureza Vickers (HV) realizados nas amostras soldadas dos aços IF, medida da largura da ZTA em seção transversal ao cordão de solda.

\section{Resultados e Discussão}

\subsection{Caracterização do estado de entrega}

A Tabela 1 apresenta as composições químicas dos aços estudados. Destaca-se em negrito as frações do elemento estabilizante Ti no aço IF-Ti, do Nb no aço IF-Nb e do Ti e do Nb no aço IF-TiNb. Nota-se também, a diferença no teor de Mn dos aços. Os aços IF-Nb e IF-TiNb possuem quantidades significativas de Mn, enquanto o aço IF-Ti apresenta 0,10\%.

No aço IF-Ti, o primeiro composto a se formar e se tornar estável é TiN capturando praticamente todo o $\mathrm{N}$ disponível na matriz ferrítica. Enquanto que o $\mathrm{C}$ é capturado pelo Ti remanescente, que juntamente com o $\mathrm{S}$, formam carbossulfetos ( $\mathrm{Ti}_{4} \mathrm{C}_{2} \mathrm{~S}_{2}$ ). No aço IF-Nb não há formação significativa de nitretos e sim de carbonetos, principalmente, $\mathrm{NbC}$, sendo que sua formação durante resfriamento no equilíbrio é favorecida antes da transformação de fase $\psi \rightarrow \alpha$, mas sua completa estabilização só é alcançada após a total decomposição da austenita. Enquanto que no aço IF-TiNb, constata-se a precipitação de TiN em temperaturas mais elevadas e, seguidamente, o Ti remanescente, juntamento com o $\mathrm{S}$, captura uma parte do $\mathrm{C}$ em solução sólida formando $\mathrm{Ti}_{4} \mathrm{C}_{2} \mathrm{~S}_{2}$. Entretanto, boa parte do $\mathrm{C}$ neste tipo de aço (IF-TiNb) é capturado pelo $\mathrm{Nb}$ formando $\mathrm{NbC}$.

Tabela 1. Composição química dos aços IF estudados neste trabalho (\%massa).

\begin{tabular}{cccccccccccc}
\hline Aço & $\mathbf{C}$ & $\mathbf{N}_{\mathbf{2}}{ }^{*}$ & $\mathbf{S i}$ & $\mathbf{M n}$ & $\mathbf{P}$ & $\mathbf{S}$ & $\mathbf{A l}$ & $\mathbf{N b}$ & $\mathbf{T i}$ & $\mathbf{M o}$ \\
IF-Ti & 0,004 & 47 & 0,0289 & $\mathbf{0 , 1 0 4}$ & 0,0135 & 0,0107 & 0,0343 & 0,003 & $\mathbf{0 , 0 5 7 7}$ & 0,0132 \\
IF-Nb & 0,0037 & 29 & 0,0196 & $\mathbf{0 , 7 2 2}$ & 0,083 & 0,0166 & 0,0369 & $\mathbf{0 , 0 0 6 4}$ & 0,0008 & 0,012 \\
IF-TiNb & 0,004 & 19 & 0,0145 & $\mathbf{0 , 6 6 7}$ & 0,0282 & 0,012 & 0,0284 & $\mathbf{0 , 0 1 8 7}$ & $\mathbf{0 , 0 1 7 2}$ & 0,0107 \\
\hline$N_{2}^{*}=$ concentração em ppm (partes por milhão) & & & & & & & &
\end{tabular}

Na Figura 2 apresentam-se as microestruturas dos aços IF no estado de entrega. Observa-se que as microestruturas são constituídas por uma matriz ferrítica, o que era esperado em função de suas composições químicas e processamento termomecânico [18]. Na Tabela 2 apresentam-se os valores dos tamanhos médios dos grãos ferríticos e valores médios de microdureza Vickers. Destaca-se a diferença no tamanho médio dos grãos ferríticos, sendo que os aços IF-Nb e IF-TiNb apresentam grãos menores e mais irregulares do que o aço IF-Ti, que por sua vez apresenta uma estrutura ferrítica equiaxial bem definida. Isto se deve, principalmente, ao efeito do ancoramento dos contornos de grãos ocasionado pelos átomos de $\mathrm{Nb}$ dissolvidos em solução sólida (aumento da temperatura de não recristalização durante a laminação controlada) e pela precipitação de $\mathrm{NbC}$ nos contornos de grãos durante a transformação, resultando em uma estrutura mais refinada, com uma maior densidade de contornos de grãos [19-21]. 
Além disso, os precipitados formados durante o processamento do aço IF-Ti, onde o C pode ser estabilizado pela formação de carbonetos ( $\mathrm{TiC}$ ) e/ou carbossulfetos $\left(\mathrm{Ti}_{4} \mathrm{C}_{2} \mathrm{~S}_{2}\right)$ e o $\mathrm{N}$ estabilizado pela formação de nitreto de titânio (TiN), são mais grosseiros do que os precipitados de $\mathrm{NbC}$ formados nos aços IF-Nb e IF-TiNb. Com isso, os finos precipitados de $\mathrm{NbC}$ formados nos aços IF-Nb e IF-TiNb, distribuídos ao longo da microestrutura do material, funcionam como barreiras mais efetivas à migração dos contornos de alto ângulo nas etapas de recristalização e crescimento de grão durante o recozimento no processo de fabricação [12,22].

As microestruturas mais refinadas dos aços IF-Nb e IF-TiNb no estado de entrega refletem nos resultados dos ensaios de microdureza Vickers, de forma que quanto mais refinada a microestrutura, maiores são os valores de microdureza. Todavia, nota-se que a média da microdureza Vickers do aço IF-TiNb é um pouco menor em relação à do aço IF-Nb, apesar daquele ter o menor tamanho de grão ferrítico. Porém, observa-se que o desvio padrão do aço IF-TiNb é mais elevado, portanto, não se pode afirmar que a sua microdureza é realmente inferior à do aço IF-Nb.
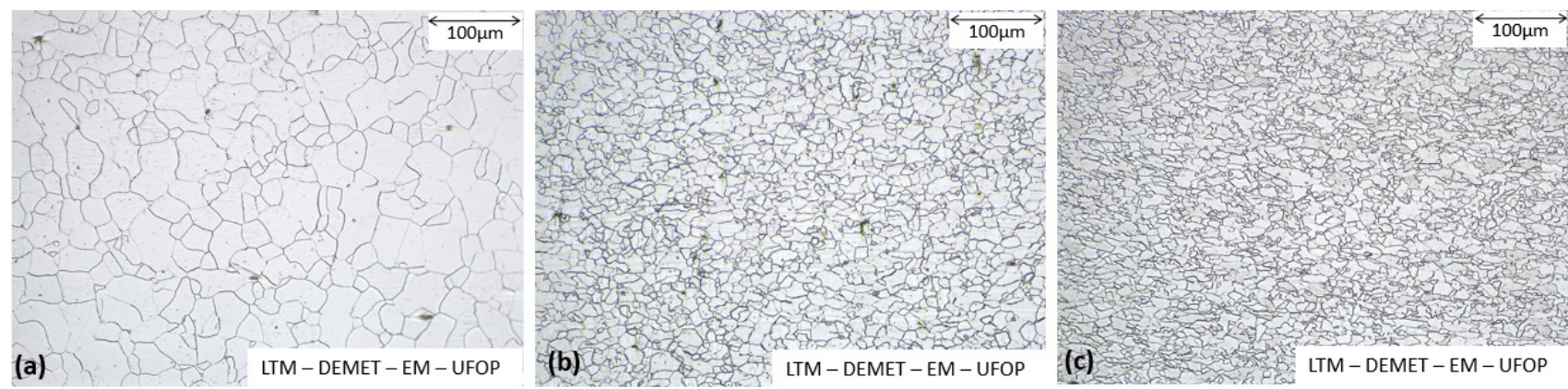

Figura 2. Microestruturas do estado de entrega - MO - Nital 2\%-200x: (a) IF-Ti; (b) IF-Nb; (c) IF-TiNb.

Tabela 2. Média das microdurezas Vickers (HV) e tamanho médio dos grãos ferríticos das microestruturas obtidas para os aços IF em seu estado de entrega.

\begin{tabular}{ccc}
\hline Aço & Tamanho de grão médio $(\boldsymbol{\mu m})$ & Microdureza Vickers (HV) \\
IF-Ti & $25 \pm 2$ & $95 \pm 5$ \\
IF-Nb & $11,0 \pm 0,8$ & $134 \pm 4$ \\
IF-TiNb & $9 \pm 1$ & $125 \pm 10$ \\
\hline
\end{tabular}

\subsection{Caracterização da cinética de transformação de fases}

Os gráficos (a), (b) e (c) da Figura 3 apresentam as temperaturas críticas de início (Ar3) e fim (Ar1) da decomposição da austenita em função das diferentes taxas de resfriamento para os aços IF-Ti, IF-Nb e IF-TiNb, respectivamente. Após determinação das temperaturas críticas em função da taxa de resfriamento contínuo, foi possível propor uma relação empírica entre as temperaturas críticas $(T)$ e a taxa de resfriamento (taxa) dada pela Equação 2. Os valores das constantes de ajuste obtidos para Ar3 e Ar1 de cada aço IF são apresentados na Tabela 3 e os ajustes podem ser visualizados nos gráficos da Figura 3.

Observa-se que com o aumento da taxa de resfriamento, as transformações começam e terminam em temperaturas mais baixas, resultando em um maior grau de super-resfriamento da austenita. Além disso, nota-se que os aços IF-Nb e IF-TiNb são mais sensíveis ao efeito da taxa de resfriamento, visto que suas temperaturas críticas, Ar3 e Ar1, variam mais fortemente com o aumento da taxa de resfriamento.

Nota-se, também, que as temperaturas críticas obtidas para o aço IF-Ti passam a diminuir mais significativamente para taxas superiores a $10^{\circ} \mathrm{C} / \mathrm{s}$. Para o aço IF-Nb, observa-se uma tendência semelhante ao que ocorre com o IF-Ti, enquanto que para o aço IF-TiNb, verifica-se uma maior sensibilidade em relação ao abaixamento das temperaturas críticas a partir de taxas mais lentas. Isto aconteceria porque com o aumento da velocidade de resfriamento há um atraso na precipitação de $\mathrm{NbC}$, logo o Nb permanece em solução sólida, contribuindo ainda mais para o abaixamento das temperaturas críticas [20,23].

Tabela 3. Equações empíricas que relacionam as temperaturas críticas e a taxa de resfriamento.

\begin{tabular}{ccc}
\hline Aço & Ar3 & Ar1 \\
IF-Ti & $T=970,7+35,3 * \exp (-0,099 * \operatorname{taxa})$ & $T=783,5+66,8 * \exp (-0,033 * \operatorname{taxa})$ \\
IF-Nb & $T=857,2+125,9 * \exp (-0,019 * \operatorname{tax} a)$ & $T=559,0+274,6 * \exp (-0,040 * \operatorname{taxa})$ \\
IF-TiNb & $T=813,7+244,8 * \exp (-0,563 * \operatorname{tax} a)$ & $T=651,7+185,4 * \exp (-0,384 * \operatorname{taxa})$ \\
\hline
\end{tabular}



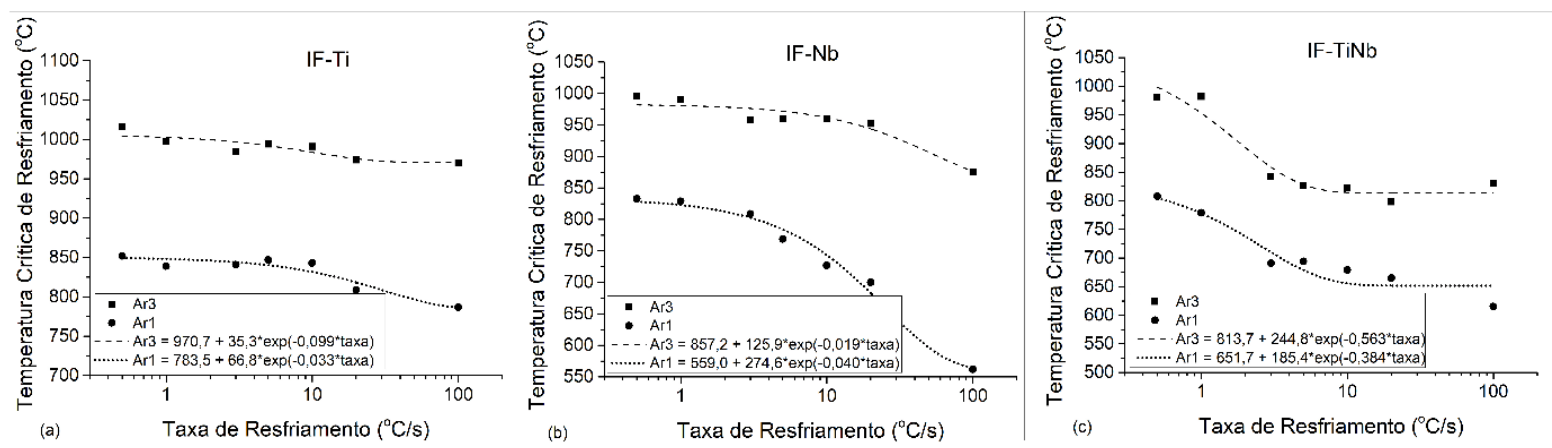

Figura 3. Temperaturas críticas no resfriamento em função da taxa de resfriamento com ajuste da Equação 2: (a) IF-Ti; (b) IF-Nb; (c) IF-TiNb.

O aço IF-Ti, em função da baixa concentração de $\mathrm{Nb}$, possui pouco desse elemento em solução sólida. Como a quantidade de $\mathrm{Mn}$ para esse aço é mais baixa, infere-se que a sua concentração em solução sólida também será pequena. Além disso, o Ti, na temperatura de austenitização utilizada neste trabalho $\left(1100{ }^{\circ} \mathrm{C}\right)$, está majoritariamente na forma de nitretos (TiN), contribuindo pouco para sua presença em solução sólida [3,12]. Assim, como há pouco Nb e Mn em solução sólida, mesmo para taxas de resfriamento mais elevadas, a cinética de decomposição da austenita pós-soldagem não é fortemente afetada, justificando o comportamento do gráfico de temperaturas críticas versus taxa de resfriamento do aço IF-Ti.

$\mathrm{O}$ aço IF-Nb possui maior quantidade de $\mathrm{Nb}$ e $\mathrm{Mn}$, logo esses elementos em solução sólida dificultariam mais a decomposição da austenita pós-soldagem e isto justificaria a queda das temperaturas críticas em relação ao aço estabilizado apenas ao Ti (IF-Ti). Ademais, o maior teor de $\mathrm{Mn}$ nestes aços IF também é uma importante contribuição para esse abaixamento das temperaturas críticas no resfriamento contínuo, pois além da sua possível presença em solução sólida, o Mn é um elemento Y-gêneo e, portanto, auxilia no atraso da decomposição austenítica [24].

Por fim, o aço IF-TiNb possui Mn próximo do IF-Nb, mas tem uma ordem de grandeza a mais de $\mathrm{Nb}$. A literatura mostra que para a concentração de $\mathrm{Nb}$ presente nos aços IF-Nb e IF-TiNb, na temperatura de austenitização avaliada neste trabalho, haverá dissolução de $\mathrm{NbC}$ na austenita e o $\mathrm{Nb}$ em solução sólida, apesar de ser $\alpha$-gêneo, dificulta o processo difusional dos átomos de $\mathrm{C}$, retardando a decomposição da austenita pós-soldagem. Esse efeito é mais intenso no aço IF-TiNb, justamente por ele apresentar maior quantidade de $\mathrm{Nb}[12,19-21,25]$

As Figuras 4 a 6 apresentam as micrografias dos corpos dilatométricos para o aço IF-Ti, IF-Nb e IF-TiNb, respectivamente. Nota-se para o aço IF-Ti, a obtenção de uma estrutura ferrítica mais grosseira com grãos bem definidos, enquanto que as microestruturas dos aços IF-Nb e IF-TiNb, também compostas de ferrita, se apresentam mais refinadas e mais irregulares. Constata-se que à medida que a taxa de resfriamento aumenta, o tamanho médio dos grãos ferríticos diminui. Isto porque com a diminuição da temperatura de início de transformação para taxas de resfriamento mais elevadas, espera-se que o raio crítico de nucleação da ferrita diminua, promovendo assim um maior número de núcleos da nova fase aptos ao crescimento.

Como o aço IF-Ti é pouco sensível ao efeito da taxa de resfriamento, a mudança morfológica é pequena com o aumento da taxa. A mudança de morfologia nos aços IF-Nb e IF-TiNb pode estar associada com a presença de Nb em solução sólida, dificultando a formação de ferrita poligonal em aços microligados e favorecendo a formação de estruturas ferríticas não poligonais [26-30].

A Figura 7 apresenta a média dos valores de microdureza Vickers obtidos para os CPs provenientes dos ensaios dilatométricos. Observa-se que a microdureza aumenta à medida que a taxa de resfriamento aumenta. Além disso, verifica-se que os valores de microdureza para os aços IF-Nb e IF-TiNb, em todas as condições de resfriamento, são maiores em comparação com os do aço IF-Ti. A maior densidade de contornos de grãos nas microestruturas dos aços IF-Nb e IF-TiNb e o efeito de endurecimento por solução sólida do $\mathrm{Mn}$, fazem com que suas resistências mecânicas sejam maiores. Além disso, o endurecimento por precipitação das finas partículas de NbC formadas nos aços IF-Nb e IF-TiNb também contribui para o aumento da resistência mecânica desses aços. 


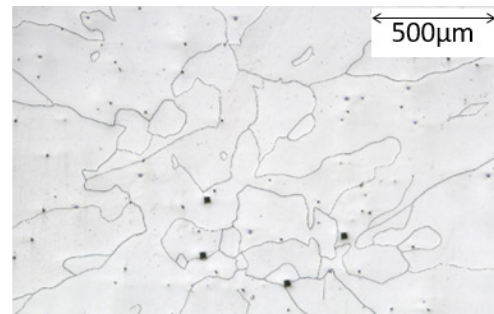

(a)

LTM - DEMET - EM - UFOP

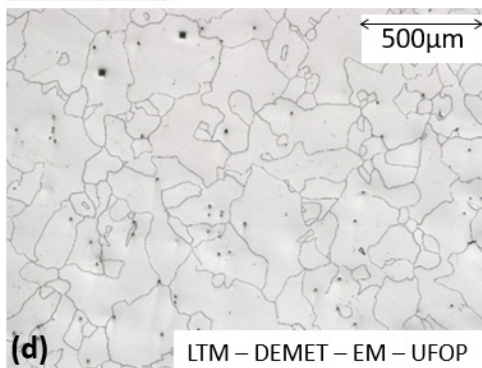

(d)
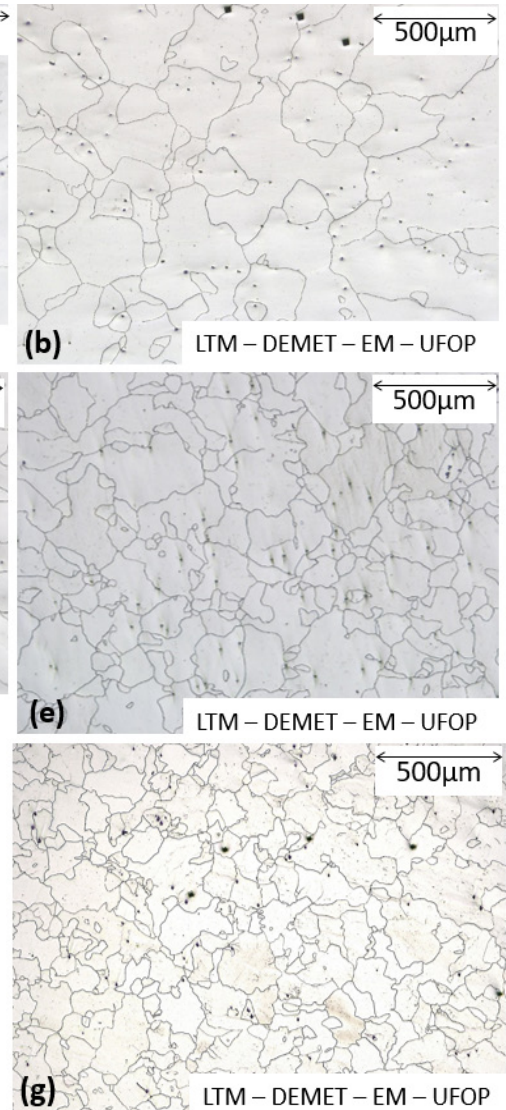

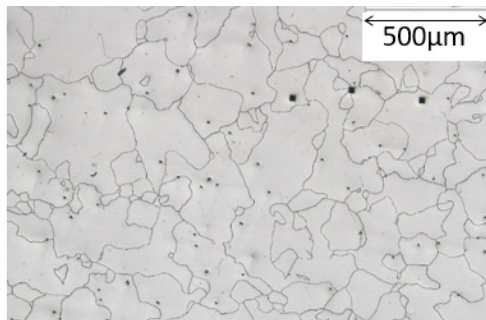

(c) LTM-DEMET-EM-UFOP

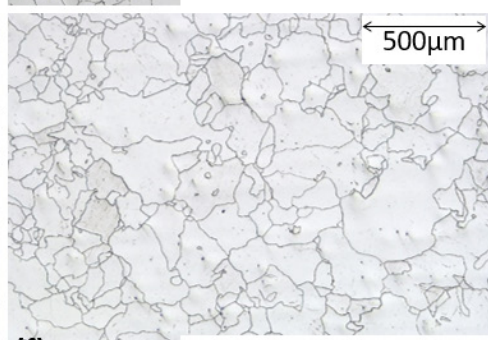

(f)

Figura 4. IF-Ti: MO - Nital $2 \%-50 \mathrm{x}-$ (a) $0,5^{\circ} \mathrm{C} / \mathrm{s}$; (b) $1{ }^{\circ} \mathrm{C} / \mathrm{s}$; (c) $3{ }^{\circ} \mathrm{C} / \mathrm{s}$; (d) $5{ }^{\circ} \mathrm{C} / \mathrm{s}$; (e) $10^{\circ} \mathrm{C} / \mathrm{s}$; (f) $20^{\circ} \mathrm{C} / \mathrm{s}$; (g) $100{ }^{\circ} \mathrm{C} / \mathrm{s}$.
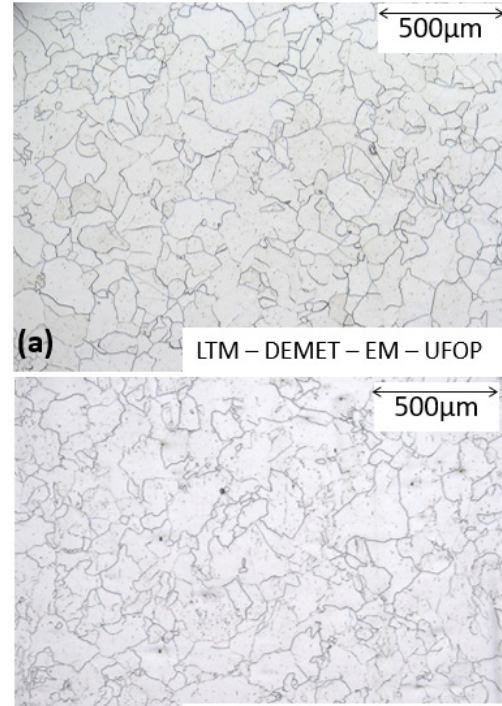

(d) LTM - DEMET - EM - UFOP
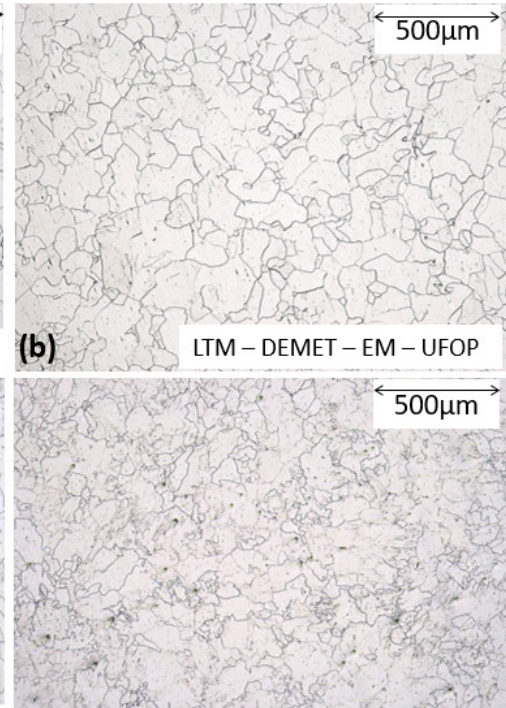

(e) LTM - DEMET - EM - UFOP

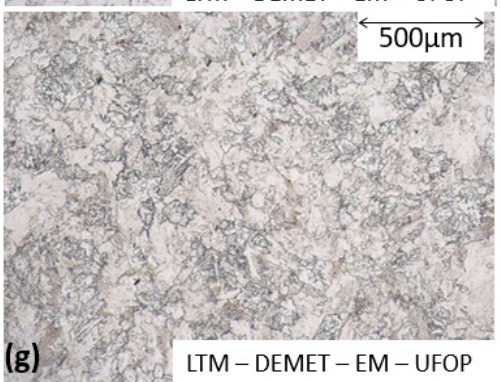

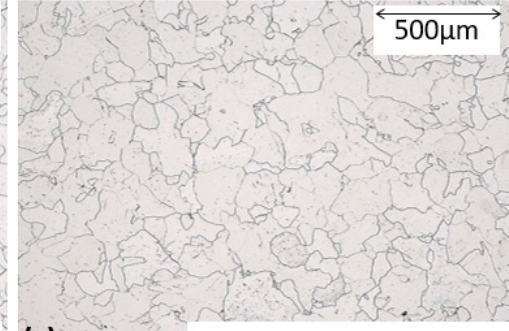

(c) LTM - DEMET - EM - UFOP

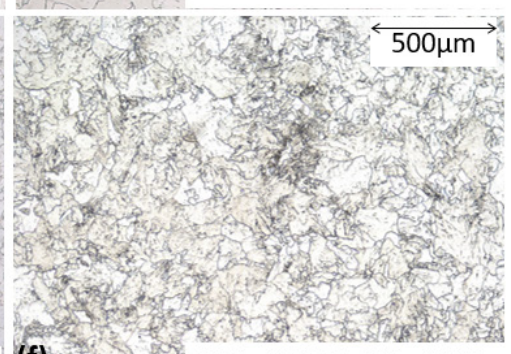

(f) $\quad$ LTM-DEMET-EM-UFOP

Figura 5. IF-Nb: MO - Nital $2 \%-50 \mathrm{x}-$ (a) $0,5^{\circ} \mathrm{C} / \mathrm{s}$; (b) $1{ }^{\circ} \mathrm{C} / \mathrm{s}$; (c) $3{ }^{\circ} \mathrm{C} / \mathrm{s}$; (d) $5{ }^{\circ} \mathrm{C} / \mathrm{s}$; (e) $10^{\circ} \mathrm{C} / \mathrm{s}$; (f) $20^{\circ} \mathrm{C} / \mathrm{s}$; (g) $100^{\circ} \mathrm{C} / \mathrm{s}$. 


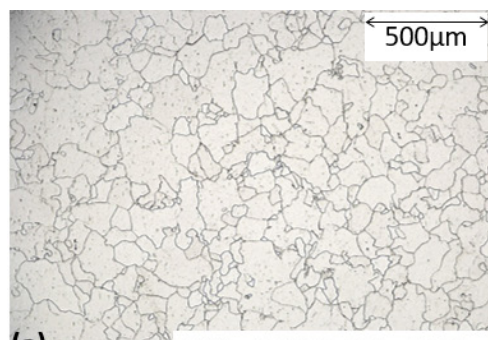

(a)

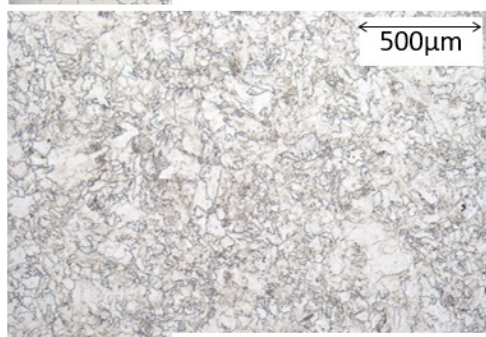

(d)

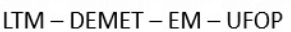

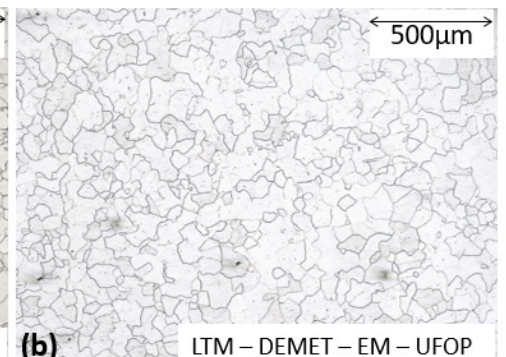

(b)

LTM - DEMET - EM - UFOP

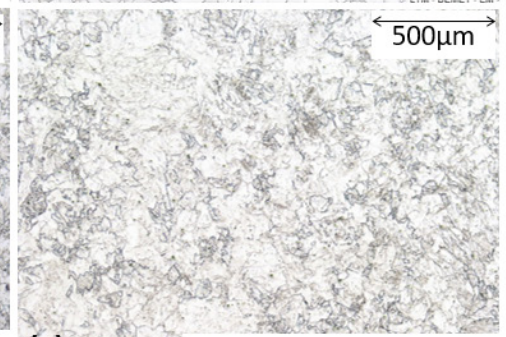

(e)
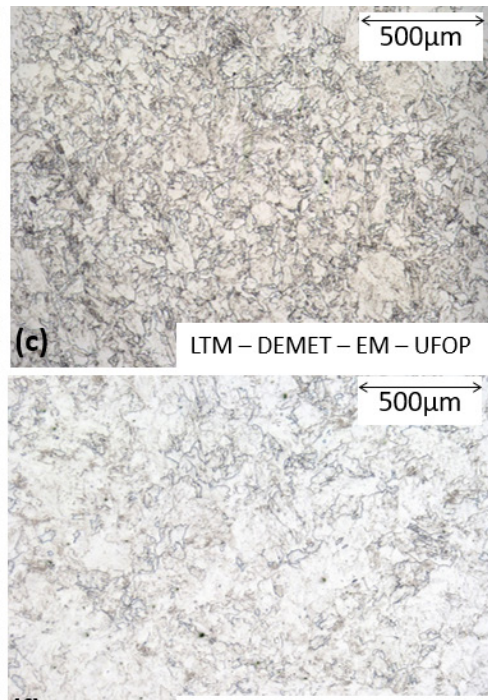

(f)

LTM - DEMET - EM - UFOP

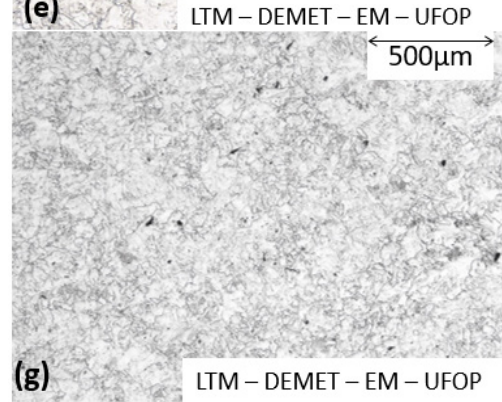


pode ser expressa pela Equação 3, onde $T \gamma$ é a temperatura de austenitização, que no presente trabalho é $1100{ }^{\circ} \mathrm{C}$, taxa é a taxa de resfriamento contínuo correspondente a cada ciclo térmico estudado e $t$ é o tempo decorrido do início do resfriamento. De posse da Equação 3, determinou-se as temperaturas de início e fim de formação da ferrita a partir do modelo JMAK para as taxas analisadas para os três aços IF estudados.

$T=T_{\gamma}+\left(-\operatorname{tax} a^{*} t\right)$

Entretanto um modelo empírico eficiente permitiria prever as temperaturas críticas de transformação de fase $\gamma \rightarrow \alpha$ póssoldagem para uma taxa qualquer no intervalo de dados estudados. Com isso, buscou-se fazer uma simulação utilizando a Equação 2 para uma possível obtenção de diagramas TRC calculados.

A Figura 10 apresenta os diagramas TRC calculados para os três tipos de aços IF. Verifica-se que tanto as temperaturas críticas determinadas experimentalmente como a simulação para obtenção do TRC calculado, considerando o modelo empírico dado pela Equação 2, estão bem ajustadas umas com as outras e que, apesar dos ensaios terem sido realizados apenas para sete taxas, é possível obter uma previsibilidade da cinética de transformação de fase $\psi \rightarrow \alpha$ para uma taxa qualquer dentro do intervalo de 0,5 a $100^{\circ} \mathrm{C} / \mathrm{s}$, considerando o diagrama calculado pelo modelo empírico. Com isso, os diagramas TRC obtidos a partir das equações empíricas relacionados com as microestruturas resultantes podem ser adaptados e contribuir para a previsibilidade da cinética de transformação de fase $\gamma \rightarrow \alpha$ nos processos de soldagem dos aços IF.

Observa-se, também, que as temperaturas críticas determinadas experimentalmente e as determinadas pelo método JMAK no diagrama TRC do aço IF-Ti estão mais bem ajustadas umas com as outras do que as dos aços IF-Nb e IF-TiNb. Isso porque, conforme foi possível perceber a partir do gráfico da Figura 3, os aços IF-Nb e IF-TiNb são mais sensíveis ao efeito da taxa de resfriamento e, considerando que a Equação 1 de JMAK foi descrita para transformações em processos isotérmicos, era de se esperar esse menor ajuste entre as temperaturas críticas obtidas experimentalmente com as determinadas pelo modelo JMAK.
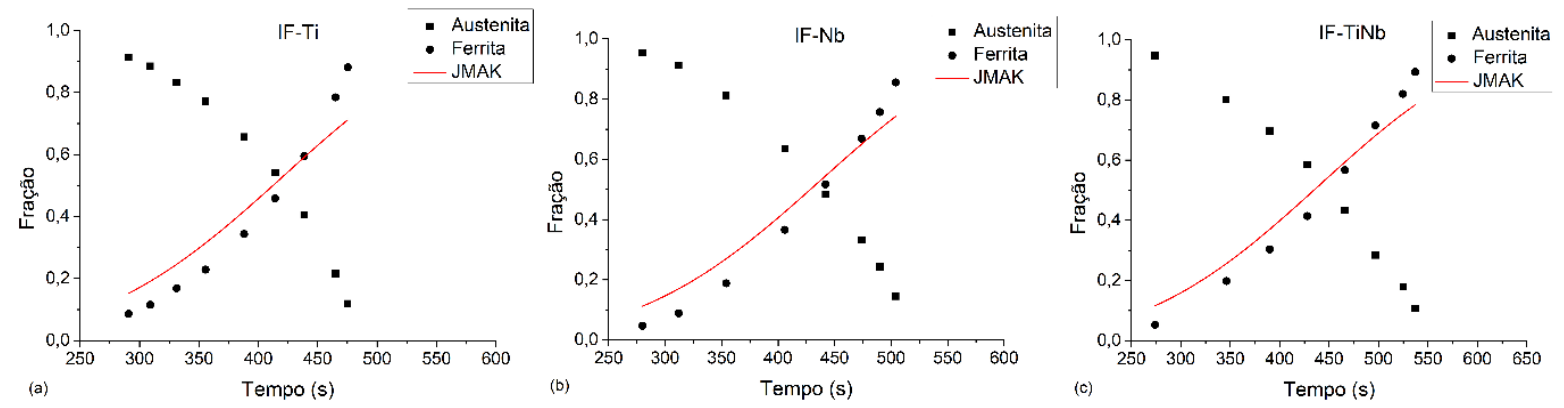

Figura 8. Gráficos Fração em função do Tempo das amostras dos aços IF resfriadas a uma taxa constante de $0,5^{\circ} \mathrm{C} / \mathrm{s}$ e ajustes dos dados considerando o modelo JMAK (Eq. (A)): (a) IF-Ti; (b) IF-Nb; (c) IF-TiNb.

Tabela 4. Parâmetros obtidos a partir do ajuste pela modelo clássico de JMAK dado pela Equação 1 para os aços IF-Ti, IF-Nb e IF-TiNb.

\begin{tabular}{|c|c|c|c|c|c|c|c|c|}
\hline \multicolumn{2}{|c|}{$\begin{array}{l}\text { Taxa de Resfriamento } \\
\qquad\left({ }^{\circ} \mathrm{C} / \mathrm{s}\right)\end{array}$} & 0,5 & 1 & 3 & 5 & 10 & 20 & 100 \\
\hline \multirow{3}{*}{ IF-Ti } & $k$ & $1 \times 10^{-11}$ & $2 \times 10^{-11}$ & $6 \times 10^{-12}$ & $3 \times 10^{-10}$ & $3 \times 10^{-8}$ & $2 \times 10^{-8}$ & $1 \times 10^{-2}$ \\
\hline & $\mathrm{n}$ & 4 & 5 & 6 & 5,8 & 5,7 & 7,1 & 5,2 \\
\hline & $\mathrm{R}^{2}$ & 0,88124 & 0,92828 & 0,89795 & 0,98814 & 0,996 & 0,99416 & 0,99681 \\
\hline \multirow{3}{*}{$\mathrm{IF}-\mathrm{Nb}$} & $\mathrm{k}$ & $9 \times 10^{-12}$ & $5 \times 10^{-11}$ & $4 \times 10^{-12}$ & $3 \times 10^{-11}$ & $8 \times 10^{-9}$ & $2 \times 10^{-6}$ & $3 \times 10^{-4}$ \\
\hline & $\mathrm{n}$ & 4,1 & 4,3 & 5,9 & 6,1 & 5,6 & 4,8 & 5,7 \\
\hline & $\mathrm{R}^{2}$ & 0,93429 & 0,95623 & 0,98706 & 0,9932 & 0,97569 & 0,99098 & 0,9868 \\
\hline \multirow{3}{*}{ IF-TiNb } & k & $1 \times 10^{-10}$ & $2 \times 10^{-10}$ & $3 \times 10^{-11}$ & $3 \times 10^{-11}$ & $2 \times 10^{-11}$ & $4 \times 10^{-11}$ & $6 \times 10^{-7}$ \\
\hline & $\mathrm{n}$ & 3,7 & 4,1 & 5 & 5,6 & 6,7 & 8 & 9,9 \\
\hline & $R^{2}$ & 0,93776 & 0,98565 & 0,79664 & 0,73732 & 0,84391 & 0,93403 & 0,98799 \\
\hline
\end{tabular}



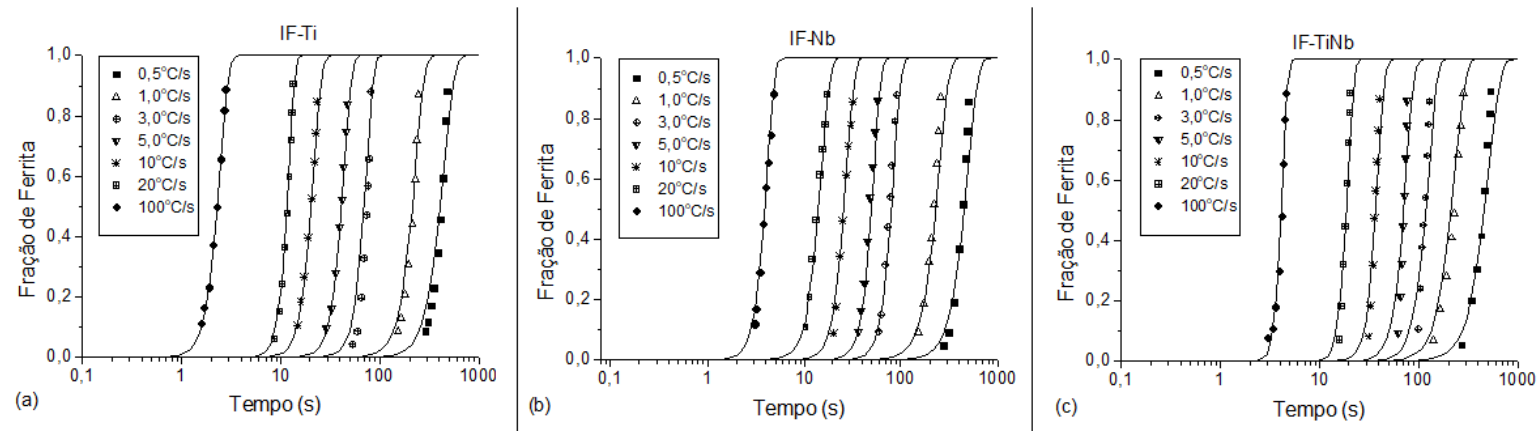

Figura 9. Simulação da cinética de formação da ferrita considerando modelo JMAK: (a) IF-Ti; (b) IF-Nb e (c) IF-TiNb.
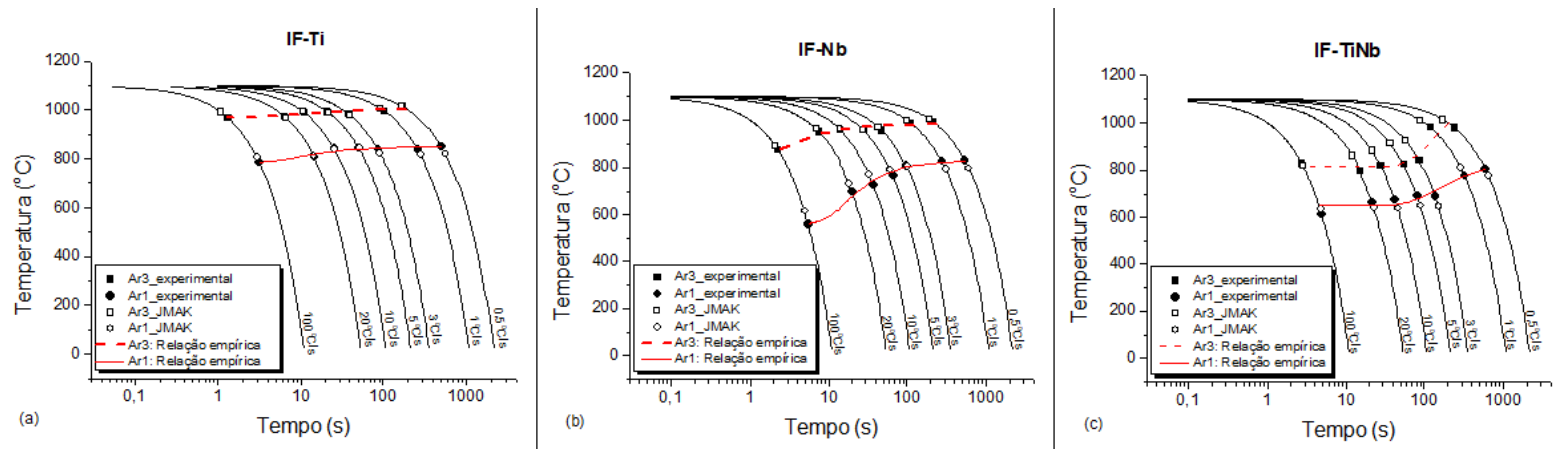

Figura 10. TRC comparativo: (a) IF-Ti; (b) IF-Nb; e (c) IF-TiNb.

\subsection{Simulação física de soldagem e validação de previsibilidade}

Os dados de temperatura em função do tempo, conforme exemplo apresentado na Figura 11 para o aço IF-TiNb, foram avaliados para os três aços IF. A temperatura de pico $\left(T_{P}\right)$ atingida na região do termopar foi igual a aproximadamente $1100{ }^{\circ} \mathrm{C}$ nos três aços, mesma temperatura de austenitização dos ensaios de dilatometria, conforme objetivado inicialmente, e considerando que a transformação $\gamma \rightarrow \alpha$ durante o resfriamento pós-soldagem vai ocorrer entre $950{ }^{\circ} \mathrm{C}$ e $550{ }^{\circ} \mathrm{C}$, a depender do tipo de aço IF, calculou-se a taxa de resfriamento neste intervalo, obtendo-se um valor médio igual a $34^{\circ} \mathrm{C} / \mathrm{s}$.

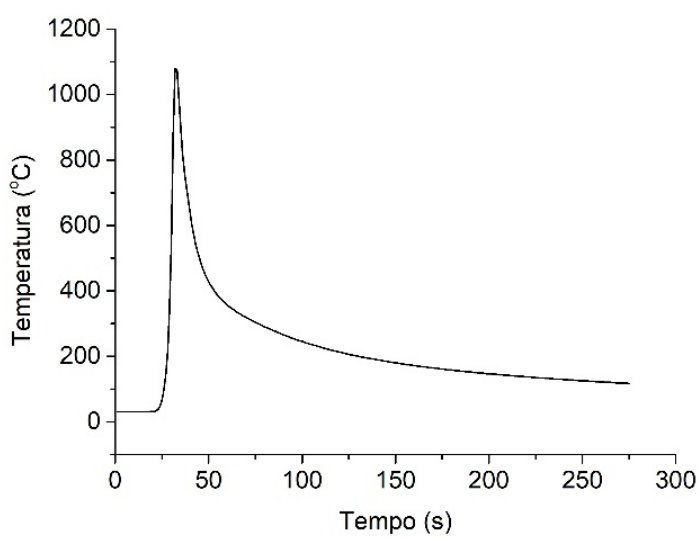

Figura 11. Exemplo de ciclo térmico de soldagem obtido experimentalmente a partir de termopar soldado na ZTA. Processo de soldagem TIG do aço IF-TiNb.

As Figuras 12 a 14 ilustram as micrografias dos aços IF-Ti, IF-Nb e IF-TiNb, respectivamente. Ressalta-se que a microestrutura da ZTA dos três aços, Figuras 12c, 13c e 14c foram obtidas nas regiões que tiveram os ciclos térmicos monitorados, ou seja, próximo aos termopares e a seção analisada corresponde ao corte transversal no sentido de deposição do cordão. A largura da ZTA (mm) dos aços IF-Ti, IF-Nb e IF-TiNb foram, respectivamente: 1,90 $\pm 0,1 ; 2,10 \pm 0,09$ e 2,00 $\pm 0,08$, nota-se que os valores para os três aços foram próximos, o que era esperado uma vez que os parâmetros de soldagem foram os mesmos. Ademais, a Figura 15 apresenta o perfil das microdureza Vickers (HV) obtidas para os aços IF. 

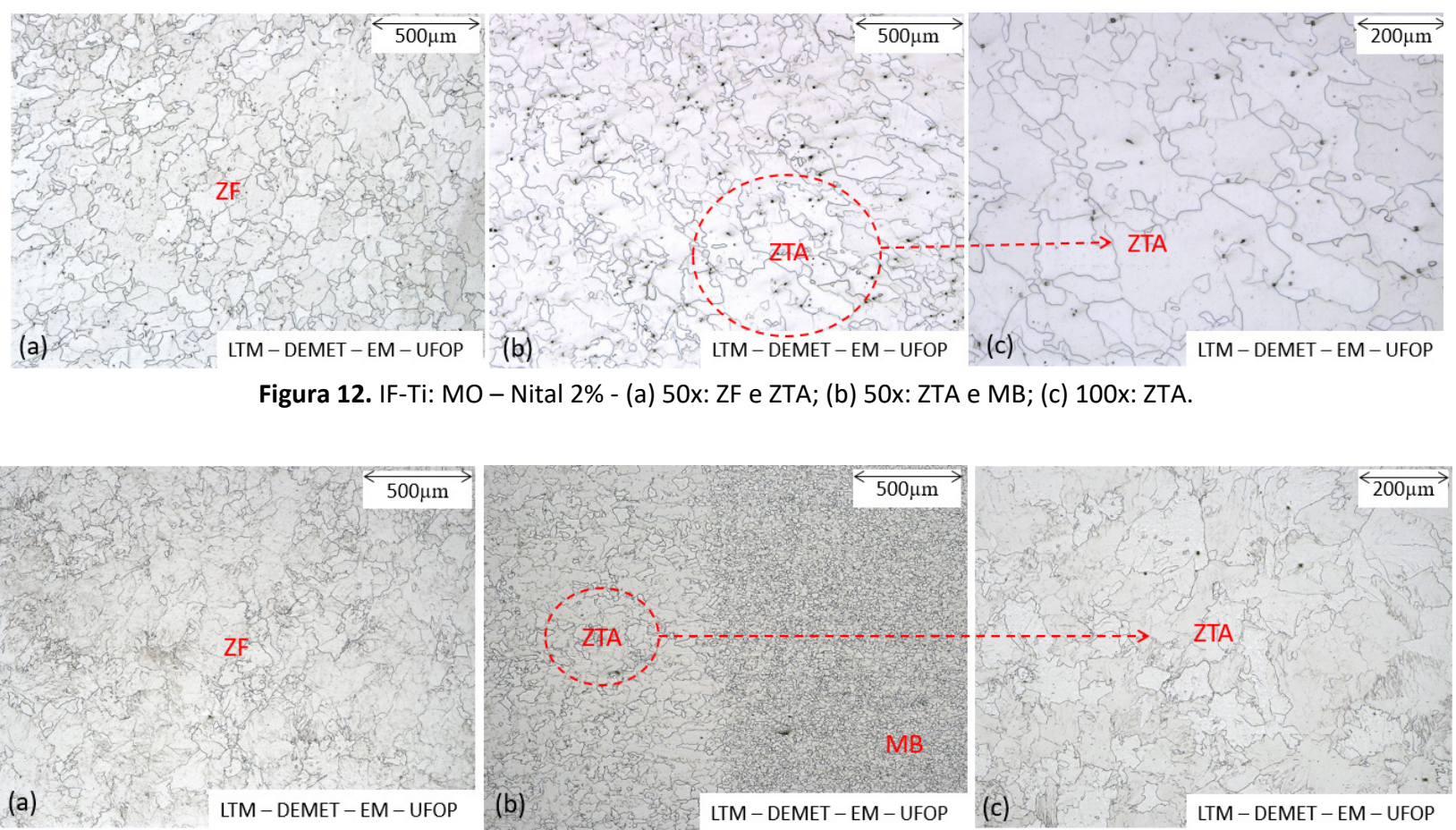

Figura 12. IF-Ti: MO - Nital 2\% - (a) 50x: ZF e ZTA; (b) 50x: ZTA e MB; (c) 100x: ZTA.

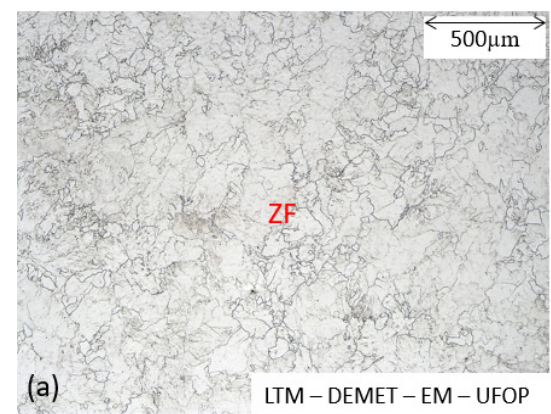

(b)

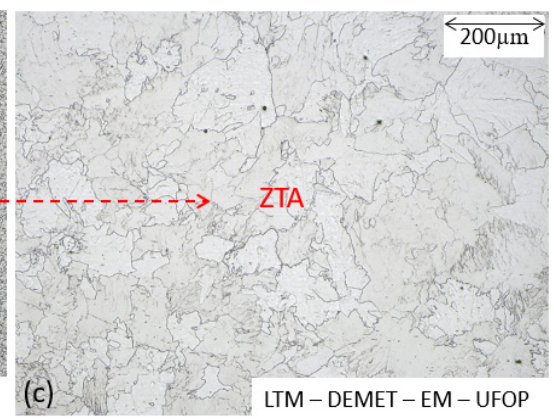

Figura 13. IF-Nb: MO - Nital 2\% - (a) 50x: ZF; (b) 50x: ZTA e MB; (c) 100x: ZTA.
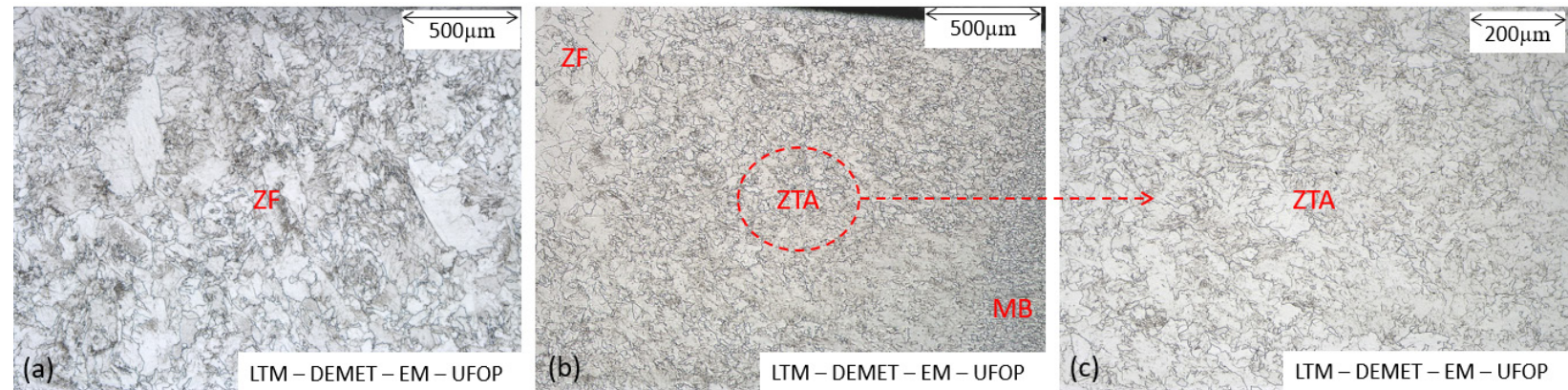

Figura 14. IF-TiNb: MO - Nital 2\% - (a) 50x: ZF; (b) 50x: ZF, ZTA e MB; (c) 100x: ZTA.
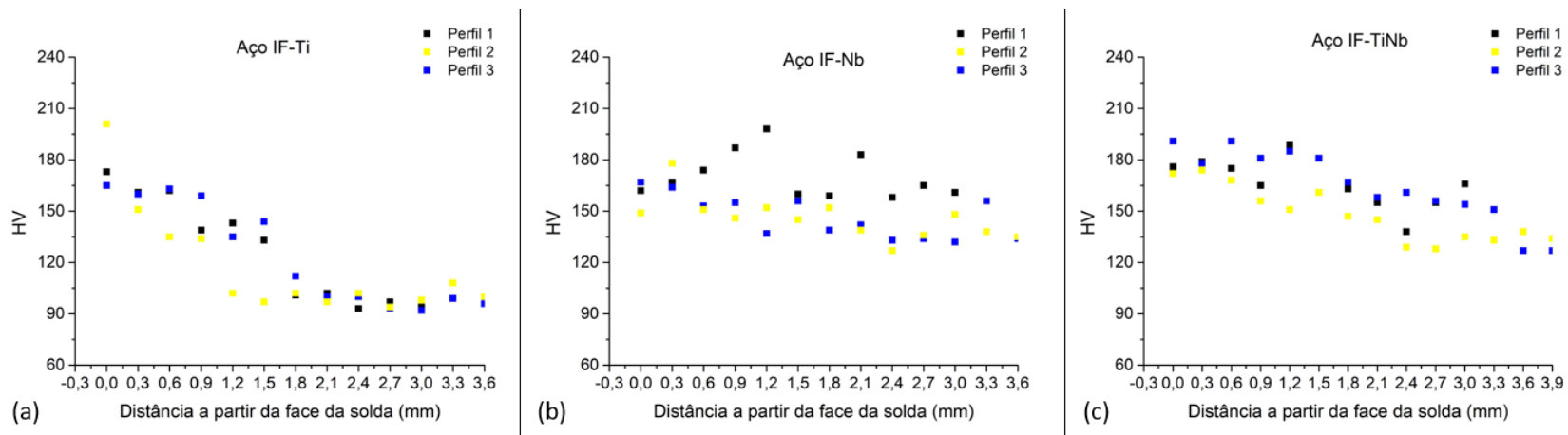

Figura 15. Perfis de microdureza Vickers (HV) obtidos segundo as direções mostradas na Figura 1c em soldas dos três aços IF: (a) IF-Ti; (b) IF-Nb; (c) IF-TiNb.

Sabendo-se que a taxa média de resfriamento da solda foi de aproximadamente $34^{\circ} \mathrm{C} / \mathrm{s}$, e tomando como parâmetro as microestruturas das amostras dilatométricas resfriadas a uma taxa de $20^{\circ} \mathrm{C} / \mathrm{s}$, é possível observar semelhanças na morfologia e nas características das microestruturas obtidas por dilatometria com aquelas obtidas a partir da simulação física da soldagem TIG. Para o aço IF-Ti, observa-se que a zona fundida (ZF) é composta por grãos ferríticos irregulares e que a região de transição (ZTA), assim como a microestrutura da amostra dilatométrica resfriada a uma taxa de $20^{\circ} \mathrm{C} / \mathrm{s}$, é composta por grãos ferríticos grosseiros que se formaram em decorrência do crescimento anterior da estrutura austenítica durante o processo de soldagem. 
Como neste tipo de aço há uma quantidade muito pequena de $\mathrm{C}$ e de elementos de liga que promovem o refino do grão, a microestrutura resultante é praticamente ferrítica com grãos maiores em comparação com os outros aços. Para as microestruturas na região da ZTA dos aços IF-Nb e IF-TiNb, verifica-se, assim como na microestrutura da amostra dilatométrica para taxa de resfriamento de $20^{\circ} \mathrm{C} / \mathrm{s}$, uma alteração na morfologia da ferrita, isto porque, a presença de $\mathrm{Nb}$ em solução sólida dificulta a formação de ferrita poligonal em aços microligados e favorece a formação de estruturas ferríticas não poligonais.

Em relação à microdureza, nota-se, como era de se esperar, que os valores diminuem à medida que se distancia do centro da solda. Além disso, observa-se que os valores de microdureza para os aços IF-Nb e IF-TiNb são maiores em comparação com os do aço IF-Ti, isto porque a presença de estruturas ferríticas não poligonais e o efeito de endurecimento por solução sólida do $\mathrm{Mn}$ e das finas partículas de $\mathrm{NbC}$, fazem com que suas resistências mecânicas sejam maiores. Na região com temperatura monitorada, os valores de microdureza foram comparados àqueles obtidos em amostras de dilatometria com taxa de resfriamento mais próxima, Tabela 5. A análise comparativa dos valores da Tabela 5 para os três aços IF complementa a avaliação metalográfica, uma vez que microestruturas semelhantes foram obtidas nos corpos de provas de dilatometria e na região monitorada da ZTA, as diferenças entre os valores de microdureza podem ser atribuídas às diferentes taxas de resfriamento.

Ademais, de posse das equações empíricas que relacionam as temperaturas críticas e a taxa de resfriamento (Tabela 3), foi possível calcular as temperaturas críticas, Ar3 e Ar1, para cada um dos aços estudados. As temperaturas críticas encontradas foram ligeiramente menores do que as temperaturas críticas obtidas para a taxa dilatométrica de $20{ }^{\circ} \mathrm{C} / \mathrm{s}$ o que, conforme apresentado pelas micrografias, acarreta em uma estrutura um pouco mais refinada e com uma maior dureza (Tabela 5) em função do abaixamento das temperaturas críticas. Portanto, a metodologia apresentada para a previsibilidade da microestrutura na ZTA dos diferentes aços IF foi aplicada com sucesso.

Tabela 5. Comparação entre os valores de microdureza Vickers obtidos na região monitorada da ZTA e nos corpos de provas de dilatometria para os aços IF-Ti, IF-Nb e IF-TiNb.

\begin{tabular}{|c|c|c|}
\hline \multirow{2}{*}{ Amostra } & \multicolumn{2}{|c|}{ Microdureza Vickers (HV) } \\
\hline & ZTA: $\left(\mathrm{Tp} 1100^{\circ} \mathrm{C}\right), \mathrm{Tx}$. Resfriamento $34^{\circ} \mathrm{C} / \mathrm{s}$ & Dilatometria: $\left(\operatorname{Tp} 1100^{\circ} \mathrm{C}\right), \mathrm{Tx}$. Resfriamento $20^{\circ} \mathrm{C} / \mathrm{s}$ \\
\hline IF-Ti & 94 & 87 \\
\hline $\mathrm{IF}-\mathrm{Nb}$ & 161 & 142 \\
\hline IF-TiNb & 166 & 146 \\
\hline
\end{tabular}

\section{Conclusões}

Obteve-se uma equação empírica que correlacionou de maneira satisfatória as temperaturas críticas de início e final de decomposição da austenita com a taxa de resfriamento e, considerando a relação entre temperatura e tempo, foi possível simular um diagrama TRC calculado para os três aços IF estudados.

Verificou-se que tanto as temperaturas críticas determinadas experimentalmente quanto a simulação para obtenção do diagrama TRC calculado a partir do modelo empírico foram bem ajustadas umas com as outras e que, apesar dos ensaios terem sido realizados para taxas específicas, é possível obter uma previsibilidade da cinética de transformação de fase $\gamma \rightarrow \alpha$, considerando o diagrama calculado pelo modelo empírico, para uma taxa qualquer dentro do intervalo de 0,5 a $100{ }^{\circ} \mathrm{C} / \mathrm{s}$. Ademais, observou-se que as temperaturas críticas determinadas experimentalmente e as determinadas pelo modelo JMAK no diagrama TRC dos aços IF-Ti e IF-Nb estão mais bem ajustadas umas com as outras do que as do aço IF-TiNb, ou seja, apesar do modelo clássico JMAK até os dias atuais ainda ser muito utilizado para previsão da cinética de transformação de fases mesmo em processos não isotérmicos, este modelo clássico não prevê de maneira satisfatória a cinética para todo tipo de aço da classe IF.

Verificou-se a aplicabilidade do modelo proposto na previsão de microestruturas obtidas a partir de experimentos de soldagem TIG dos aços IF, nos quais obteve-se regiões da ZTA com temperatura de austenitização e taxa de resfriamento similares às utilizadas nos ensaios dilatométricos para validação da hipótese de previsibilidade. Mostrou-se que seria possível prever, com confiabilidade, as temperaturas críticas obtidas na ZTA a partir da soldagem desses aços IF pelo processo TIG por meio da equação empírica obtida. As microestruturas obtidas por dilatometria e aquelas obtidas na região da ZTA próxima ao termopar possuem morfologias e características semelhantes. Além disso, na região com temperatura monitorada, os valores de microdureza foram comparados àqueles obtidos em amostras de dilatometria com taxa de resfriamento mais próxima e a análise complementou a avaliação metalográfica.

\section{Agradecimentos}

À Capes, pelo financiamento da bolsa de mestrado e ao CNPq pela bolsa de produtividade em pesquisa. 


\section{Referências}

[1] Bayraktar E, Kaplan D, Devillers L, Chevalier JP. Grain growth mechanism during the welding of interstitial free steels. Journal of Materials Processing Technology. 2007;189(1-3):114-125. http://dx.doi.org/10.1016/j.jmatprotec.2007.01.012.

[2] Mukhopadhyay G, Bhattacharya S, Ray KK. Strength assessment of spot-welded sheets of interstitial free steels. Journal of Materials Processing Technology. 2009;209(4):1995-2007. http://dx.doi.org/10.1016/j.jmatprotec.2008.04.065.

[3] Bayraktar E, Chevalier JP, Kaplan D, Devillers L. Effect of alloying elements on the damage of interstitial free steels. In: Proceedings of the SEM Annual Conference; 2009; Albuquerque, New Mexico, USA. Houston: Society for Experimental Mechanics; 2009.

[4] Rao SS, Chhibber R, Arora KS, Shome M. Resistance spot welding of galvannealed high strength interstitial free steel. Journal of Materials Processing Technology. 2017;246:252-261. http://dx.doi.org/10.1016/j.jmatprotec.2017.03.027.

[5] Johnson WA, Mehl RF. Reaction kinetics in processes of nucleation and growth. Transactions of the American Institute of Mining and Metallurgical Engineers. 1939;135:416-442.

[6] Avrami MJ. Kinetics of phase change. The Journal of Chemical Physics. 1939;7(12):1103-1112. http://dx.doi.org/10.1063/1.1750380.

[7] Kolmogorov AE. On the statistical theory of crystallization of metals. Bulletin of the Academy of Sciences of the USSR, Mathematics Series. 1937;1(3):355-359.

[8] Gómez M, Medina SF, Caruana G. Modelling of phase transformation kinetics by correction of dilatometry results for a ferritic Nbmicroalloyed steel. ISIJ International. 2003;43(8):1228-1237. http://dx.doi.org/10.2355/isijinternational.43.1228.

[9] Singh SB, Krishnan K, Sahay SS. Modeling non-isothermal austenite to ferrite transformation in low carbon steels. Materials Science and Engineering A. 2007;445-446:310-315. http://dx.doi.org/10.1016/j.msea.2006.09.044.

[10] Almeida GMR, Dafé SSF, Oliveira FLG, Cota AB. Modelagem da formação não isotérmica da austenita em um aço de baixo carbono. Revista Escola de Minas. 2010;63(2):293-298. http://dx.doi.org/10.1590/S0370-44672010000200013.

[11] Lopes MMB, Cota AB. A Study of isochronal austenitization kinetics in a low carbono steel. Revista Escola de Minas. 2014;67(1):61-66. http://dx.doi.org/10.1590/S0370-44672014000100009.

[12] Lino R, Guadanini LGL, Silva LB, Neto JGC, Barbosa R. Effect of Nb and Ti addition on activation energy for austenite hot deformation. Journal of Materials Research and Technology. 2019;8(1):180-188. http://dx.doi.org/10.1016/j.jmrt.2017.11.002.

[13] American Society for Testing and Materials. ASTM E3-11: standard guide for preparation of metallographic specimens. West Conshohocken: ASTM; 2017.

[14] American Society for Testing and Materials. ASTM E384-17: standard test method for microindentation hardness of materials. West Conshohocken: ASTM; 2017.

[15] Pawłowski B. Determination of critical points of hypoeutectoid steel. Archives of Metallurgy and Materials. 2012;57(4):957-962. http://dx.doi.org/10.2478/v10172-012-0106-4.

[16] Li H, Gai K, He L, Zhang C, Cui H, Li M. Non-isothermal phase-transformation kinetics model for evaluating the austenization of $55 \mathrm{CrMo}$ steel based on Johnson-Mehl-Avrami equation. Materials \& Design. 2016;92:731-741. http://dx.doi.org/10.1016/j.matdes.2015.12.110.

[17] Shahriari B, Vafaei R, Sharifi EM, Farmanesh K. Continuous cooling transformation behavior and the kinetics of bainite formation in a bainitic-martensitic steel. International Journal of Materials Research. 2017;108(9):715-724. http://dx.doi.org/10.3139/146.111531.

[18] Saray O, Purcek G, Karaman I, Neindorf T, Maier HJ. Equal-channel angular sheet extrusion of interstitial-free steel: microstructural evolution and mechanical properties. Materials Science and Engineering A. 2011;528(21):6573-6583. http://dx.doi.org/10.1016/j.msea.2011.05.014.

[19] Lips K, Yang X, Mols K. The Effect of coiling temperature and continuous annealing on the properties of bake hardenable IF steels. Steel Research International. 1996;67(9):357-363. http://dx.doi.org/10.1002/srin.199605501.

[20] Klinkenberg C, Hulka K, Bleck W. Niobium carbide precipitation in microalloyed steel, materials technology. Microalloyed Steels. 2004;75(11):744-758.

[21] Mohrbacher H. Niobium based metallurgical concepts and strategies for the production of IF-HS and IF-BH steel grades. In: Proceedings of the International Conference on Interstitial Free Steels: Manufacturing Applications IFSTEEL-2010; 2010; Jamshedpur, India. Belgium: NiobelCon; 2010. 12 p.

[22] Dias FMS, Fonseca FAV, Hauegen CG, Lins JFC, Campos MF. Textura e Comportamento Mecânico de Aços IF Estabilizados ao Ti e Nb-Ti. Tecnologica em Metalurgia, Materiais e Mineração. 2012;9(4):294-301. http://dx.doi.org/10.4322/tmm.2012.044.

[23] Robinson IDG, Garcin T, Poole WJ. The effect of niobium on austenite decomposition in line pipe steels. In: Proceedings of the 11th International Pipeline Conference IPC 2016; 2016; Calgary, Alberta, Canada. New York: ASME; 2016. http://dx.doi.org/10.1115/IPC201664509. 
[24] Grajcar A, Zalecki W, Burian W, Kozłowska A. Phase equilibrium and austenite decomposition in advanced high-strength medium-Mn bainitic steels. Metals. 2016;6(10):248. http://dx.doi.org/10.3390/met6100248.

[25] Kim S, Lee J, Barlat F, Lee M. Transformation kinetics and density models of quenching and partitioning (Q\&P) steels. Acta Materialia. 2016;109:394-404. http://dx.doi.org/10.1016/j.actamat.2015.11.051.

[26] Thomas $\mathrm{MH}$, Michal $\mathrm{GM}$. The influence of niobium and $\mathrm{Nb}(\mathrm{C}, \mathrm{N})$ precipitation on the formation of proeutectoid ferrite in low alloy steels. In: Proceedings of the International Conference on Solid to Solid Phase Transformations; 1981; Warrendale, PA. Warrendale: AIME; 1981. p. 469-473.

[27] Fossaert C, Rees G, Maurickx T, Bhadeshia HKDH. The effect of niobium on the hardenability of microalloyed austenite. Metallurgical and Materials Transactions A. 1995;26(1):21-30. http://dx.doi.org/10.1007/BF02669791.

[28] Rees G, Perdrix J, Maurickx T, Bhadeshia $H$. The effect of niobium in solid solution on the transformation kinetics of bainite. Materials Science and Engineering: A. 1995;194(2):179-186. http://dx.doi.org/10.1016/0921-5093(94)09673-2.

[29] Tang Z, Stumpf W. The role of molybdenum additions and prior deformation on acicular ferrite formation in microalloyed Nb-Ti lowcarbon line-pipe steels. Materials Characterization. 2008;59(6):717-728. http://dx.doi.org/10.1016/j.matchar.2007.06.001.

[30] Reichert JM, Militzer M. Quantifying the effect of $\mathrm{Nb}$ and Mo and transformation products using advanced EBSD analysis. In: HSLA Steels 2015, Microalloying 2015 \& Offshore Engineering Steels 2015: Conference Proceedings; 2015; Hangzhou, Zhejiang Province, China. Pittsburgh: TMS; 2015. p. 143-149. http://dx.doi.org/10.1002/9781119223399.ch12. 